\title{
Hypertrophy of Lumbopelvic Muscles in Inactive Women: A 36-Week Pilates Study
}

\author{
Cecilia Dorado, PhD, ${ }^{\dagger \neq}$ Ana López-Gordillo, PhD, ${ }^{\ddagger}$ José A. Serrano-Sánchez, PhD, ${ }^{\dagger \neq}$ \\ José A.L. Calbet, MD, PhD, ${ }^{\dagger \neq}$ and Joaquín Sanchis-Moysi, PhD*†‡
}

Background: The use of Pilates in various fields of sport sciences and rehabilitation is increasing; however, little is known about the muscle adaptations induced by this training method.

Hypothesis: A standardized Pilates training program for beginners ( 9 months; 2 sessions of 55 minutes per week) will increase the muscle volume and reduce potential side-to-side asymmetries of the quadratus lumborum, iliopsoas, piriformis, and gluteus muscles (gluteus maximus, medius, and minimus).

Study Design: Controlled laboratory study.

Level of Evidence: Level 3.

Method: A total of 12 inactive, healthy women $(35.7 \pm 5.4$ years $)$ without previous experience in Pilates were randomly selected to participate in a supervised Pilates program (36 weeks, twice weekly). Muscle volume $\left(\mathrm{cm}^{3}\right)$ was determined using magnetic resonance imaging at the beginning and end of the intervention program. Side-to-side asymmetry was calculated as [(left - right volume) $\times 100 /$ right volume].

Results: Small, nonsignificant $(P>0.05)$ differences in the volume of the quadratus lumborum, iliopsoas, piriformis, and gluteus muscles were observed between pre- and post-Pilates program timepoints. Before and after Pilates, side-to-side asymmetry was less than $6 \%$ and nonsignificant in all muscles analyzed.

Conclusion: Modern Pilates performed twice weekly for 9 months did not elicit substantial changes in the volume and degree of asymmetry of the selected lumbopelvic muscles in inactive women.

Clinical Relevance: The benefits of Pilates in rehabilitation or training are likely elicited by neuromuscular rather than morphological adaptations. Pilates has no significant impact on muscle volume and does not alter side-to-side ratios in muscle volume (degree of asymmetry) of the lumbopelvic muscles.

Keywords: Pilates-based exercises; magnetic resonance imaging; muscle; hypertrophy

$\mathrm{P}$ ilates has been promoted as an effective training method to improve strength and flexibility of muscles that cross the pelvic girdle, improve balance, ${ }^{16,23}$ and decrease chronic low back pain. ${ }^{33}$ However, little is known about the muscle adaptations induced by Pilates. Growing clinical interest about this training method necessitates the description of its effects in more detail. ${ }^{4}$

The assessment of muscle volume with magnetic resonance imaging (MRI) or computed tomography is the most precise and accurate method to detect changes in muscle size, particularly when using manual segmentation analysis. ${ }^{2,21}$ Alternately, automatic muscle segmentation improves processing time at the expense of decreasing precision. ${ }^{2,21}$ On the other hand, a single cross-sectional area (CSA) may not be representative of the entire muscle size and may not detect regional changes. ${ }^{2,21}$ Although muscle strength and muscle CSA are strongly associated, the measurement of muscle volume seems more appropriate than CSA to assess muscle size-strength relationships. ${ }^{1,9,22}$

Athletes participating in sports requiring repetitive and powerful unilateral trunk rotations (eg, tennis, cricket, golf,

From ${ }^{\dagger}$ Research Institute of Biomedical and Health Sciences (IUIBS), University of Las Palmas de Gran Canaria, Canary Islands, Spain, ”Department of Physical Education Department, University of Las Palmas de Gran Canaria, Canary Islands, Spain, and ${ }^{\S}$ Department of Physical Performance, Norwegian School of Sport Sciences, Oslo, Norway *Address correspondence to Joaquín Sanchis-Moysi, PhD, Department of Physical Education, University of Las Palmas de Gran Canaria, Campus de Tafira, Las Palmas de Gran Canaria, 35017, Spain (email: joaquin.sanchis@ulpgc.es).

The authors report no potential conflicts of interest in the development and publication of this article. 

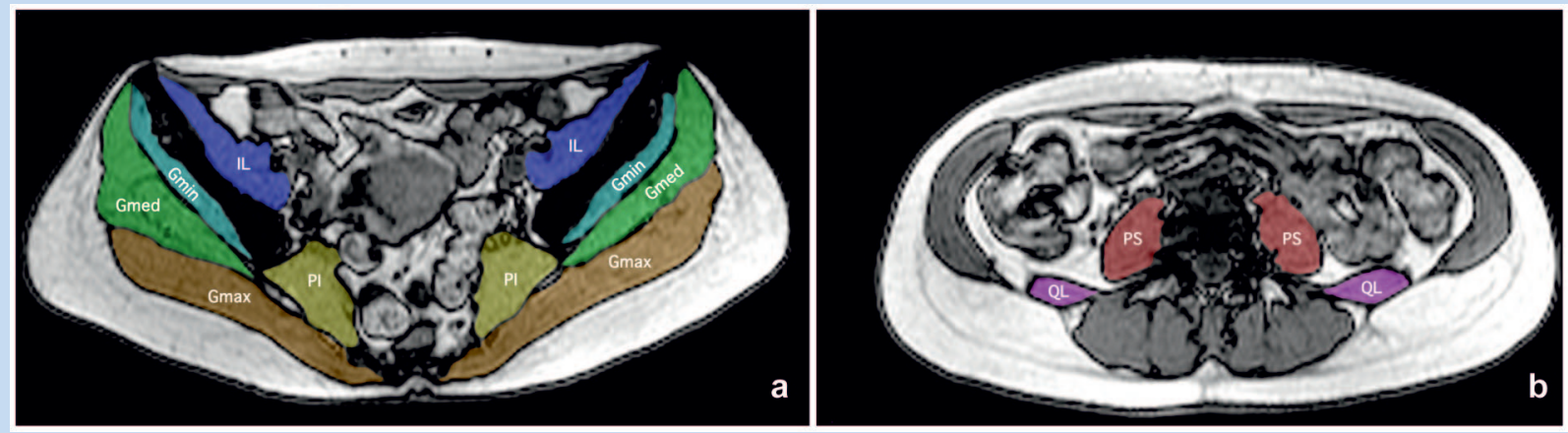

Figure 1. Cross-sectional magnetic resonance images showing the different muscle compartments measured in a physically inactive female (age, 40.3 years) before the Pilates training program. Magnetic resonance image (a) at L4 and (b) S5 levels. Gmax, gluteus maximus; Gmed, gluteus medius; Gmin, gluteus minimus; IL, iliopsoas; PI, piriformis; PS, psoas major; QL, quadratus lumborum.

soccer) develop sport-specific bilateral differences in the volume of the lumbopelvic muscles. ${ }^{7,14,26-28}$ Functionally, the quadratus lumborum and psoas muscles contribute to segmental motion control in the lumbar spine, ${ }^{15}$ whereas the piriformis and gluteus muscles provide support and maintain stability during hip movements. ${ }^{10,30}$ Side-to-side asymmetries in the volume of this musculature may predispose to pathological conditions such as low back pain ${ }^{24}$ or hip osteoarthritis. ${ }^{11,12}$ For instance, the gluteus maximus, minimus, and piriformis muscles display lower volumes in the symptomatic compared with the nonsymptomatic side of individuals with low back pain. ${ }^{29}$ In athletes, large bilateral asymmetries in the CSA of the quadratus lumborum and psoas major have also been associated with this pathology. ${ }^{13,31}$

Pilates appears to be superior to other forms of exercise for the treatment of low back pain. ${ }^{18,19}$ Compared with classic Pilates, modern Pilates is characterized by a more gradual introduction of exercises and a greater emphasis on posture, body alignment, and breathing with use of new equipment. ${ }^{32}$ Modern Pilates prioritizes the activation of the muscles stabilizing the lumbar spine and pelvis. ${ }^{32}$ However, the effects of Pilates on the lumbopelvic muscles has not been assessed in previous studies.

The main aim of the present study was to determine the effects of a standardized Pilates training program for beginners on the volume of the quadratus lumborum, iliopsoas, piriformis, and gluteus muscles in inactive, healthy women using MRI. Another aim was to assess the degree of asymmetry of these muscles and check whether the Pilates-based training method modifies potential asymmetries in this musculature. This would provide useful information for physiotherapists and Pilates practitioners. ${ }^{3}$ Given the symmetric nature of Pilates exercises and the previous findings reporting a symmetric development of the abdominal musculature, ${ }^{5}$ we hypothesized that Pilates may serve to increase muscle volume and symmetrically develop the quadratus lumborum, iliopsoas, piriformis, and gluteus muscles.

\section{METHODS}

\section{Participants}

A total of 12 healthy premenopausal women (mean \pm SD age, $35.7 \pm 5.4$ years; mean height, $164.1 \pm 5.6 \mathrm{~cm}$ ) volunteered to participate in this study. For more details regarding sample recruitment and size, please refer to Appendix 1 (available in the online version of this article). All participants gave written consent to participate in this study after being informed about the potential benefits and risks involved. This investigation was approved by the ethics committee of the University of Las Palmas de Gran Canaria.

\section{Intervention}

Participants took part in a 36-week standardized modern studio Pilates training program, twice a week, for 55 minutes each training session, as previously reported. ${ }^{5}$ The intervention was supervised by a certified Pilates trainer. A detailed description of the intervention program is provided in Appendix 1 (available online).

\section{Measures}

The Minnesota Leisure Time Physical Activity Questionnaire was used to assess physical activity during the intervention. ${ }^{6}$ Total percentage of body fat was measured using dual-energy X-ray absorptiometry (QDR-1500 Version 7.10; Hologic Corp), as described elsewhere. ${ }^{5}$

\section{Magnetic Resonance Imaging}

A 1.5-T MRI scanner (Philips Achieva 1.5 Tesla system; Philips Healthcare) was used to acquire 8-mm axial slices from the trunk and pelvis, with 2-mm interslice separation (echo time/ repetition time/alpha, $4.2 \mathrm{~ms} / 132 \mathrm{~ms} / 90^{\circ}$; field of view, $42 \mathrm{~cm}^{2}$; matrix, $256 \times 256$ pixels; in-plane spatial resolution, $1.64 \mathrm{~mm} \times$ $1.64 \mathrm{~mm}$ ), as previously reported. ${ }^{5}$ For additional information regarding the MRI assessment, refer to Appendix 1. The acquired MRI images were transferred to a computer for digital reconstruction to determine the muscle CSAs (Figure 1). 
The total volume for the quadratus lumborum, iliopsoas, piriformis, and gluteus maximus, medius, and minimus was calculated in each participant from the L1-L2 intervertebral disc to the pubic symphysis. A trained, experienced physiotherapist ${ }^{26-28}$ calculated the areas and volumes by manually outlining the MRI slices (Slice O'matic 4.3; Tomovision Inc). ${ }^{25}$ The degree of asymmetry was assessed by calculating the ratio of the volume of the right and left sides [(left - right volume $) \times 100 /$ right volume]

\section{Statistical Analysis}

Muscle volume variables were checked for normality and homoscedasticity using the Shapiro-Wilk and KolmogorovSmirnov tests with the Lilliefors correction. All variables adjusted well to the normality tests except the gluteus minimus, which was logarithmically transformed for the comparison for training (pre vs post) and side (left vs right) but keeping the original untransformed value to facilitate reading. Comparisons also presented homogeneous variances in all muscle volume variables $(P=0.15-0.94$ [Levene test]).

Results are presented as means \pm SE, unless stated otherwise. Pre- to posttraining and left to right side comparisons were carried out using analysis of variance for repeated measures with 2 factors: (1) training (pre vs post) and (2) side (left vs right). SPSS (Version 21; IBM Corp) for personal computers was used for the statistical analysis. Significant differences were assumed when $P(2$-tailed $)<0.05$. Power analyses were determined using $G *$ Power software (Version 3.1.9.2). All participants who finished the Pilates training program were included in the statistical analysis.

\section{RESULTS}

There were no significant pre- to posttraining differences in body weight $(66.7 \pm 2.5$ vs $66.5 \pm 2.6 \mathrm{~kg}$, respectively; $P=0.54)$, body mass index $\left(24.8 \pm 0.9\right.$ vs $24.7 \pm 0.9 \mathrm{~kg} / \mathrm{m}^{2}$, respectively; $\left.P=0.36\right)$, or body fat percentage $(34.6 \pm 0.7$ vs $36.7 \pm 1.3 \%$, respectively; $P=$ $0.22)$. The total, moderate, and vigorous energy expenditure was similar before and after the Pilates training program (68.6 \pm 16.1 and $57.5 \pm 11.9 \mathrm{MET} \cdot \mathrm{h}^{-1} \cdot \mathrm{wk}^{-1}$, respectively; $P=0.38$ ). The effects of Pilates on the abdominal muscles have been previously reported. ${ }^{5}$ Briefly, Pilates increased the volume of the abdominal muscles and eliminated preexisting asymmetries in this musculature.

In the present study, we report the effects on the lumbopelvic muscles. Table 1 shows the mean muscle volumes before and after Pilates training. We observed small nonsignificant changes $(P=0.10-0.97)$ after Pilates, negative for the quadratus lumborum and gluteus muscles and positive for the iliopsoas and piriformis muscles. There was no significant interaction for training by side (Table 1).
No between-side differences were observed either before or after Pilates. The degree of asymmetries ranged between $0.4 \%$ (gluteus medius) and 5.9\% (gluteus minimus). Pilates did not alter significantly the small asymmetries observed $(P=0.18-0.77)$.

\section{DISCUSSION}

The main finding of this study was that after 36 weeks of supervised modern Pilates, twice a week, the volume of the quadratus lumborum, iliopsoas, piriformis, and gluteus muscles remained unchanged. Moreover, Pilates does not seem to alter the degree of side-to-side asymmetry of these muscles. In contrast, the quadratus lumborum ${ }^{27}$ and iliopsoas muscles ${ }^{28}$ have been found to be asymmetric ( $15 \%$ and $4 \%$, respectively) in healthy men. Sex-based differences regarding physical activity at work or household activity ${ }^{17}$ or the potential for muscle hypertrophy ${ }^{8}$ might explain these differences, although further studies with a greater number of participants are needed.

The results of the present study should be interpreted considering some methodological limitations. The study was limited to a small population. On the other hand, the Pilates exercises could have not been specific enough or the exercise intensity could have been too low to induce muscle hypertrophy in the lumbopelvic muscles. However, this might not be considered a limitation of the study but rather the reality of a typical Pilates training program for beginners. The training protocol followed by the participants (exercises, intensities, and progression) was designed according to the criterion of the Pilates Method Alliance (https://www.pilatesmethodalliance .org/), an international Pilates association developed to unify the knowledge for all of the lineages and schools of Pilates. In fact, the volunteers experienced marked hypertrophy of the rectus abdominis and a little less hypertrophy of the obliques and transversus abdominis, as previously reported. ${ }^{5}$ Thus, it seems that the lack of hypertrophy of the lumbopelvic muscles in response to Pilates is more likely due to the fact that Pilates does not activate these muscles with enough intensity to elicit significant muscle hypertrophy. ${ }^{20}$ Finally, the determination of changes in muscle strength would have helped to ascertain whether the Pilates training program caused adaptations other than morphological ones (ie, neurological). However, so far, it is not possible to directly assess the strength of each muscle individually.

\section{CONCLUSION}

Modern Pilates twice a week for 9 months did not elicit hypertrophy of the quadratus lumborum, iliopsoas, piriformis, and gluteus muscles in inactive women. 


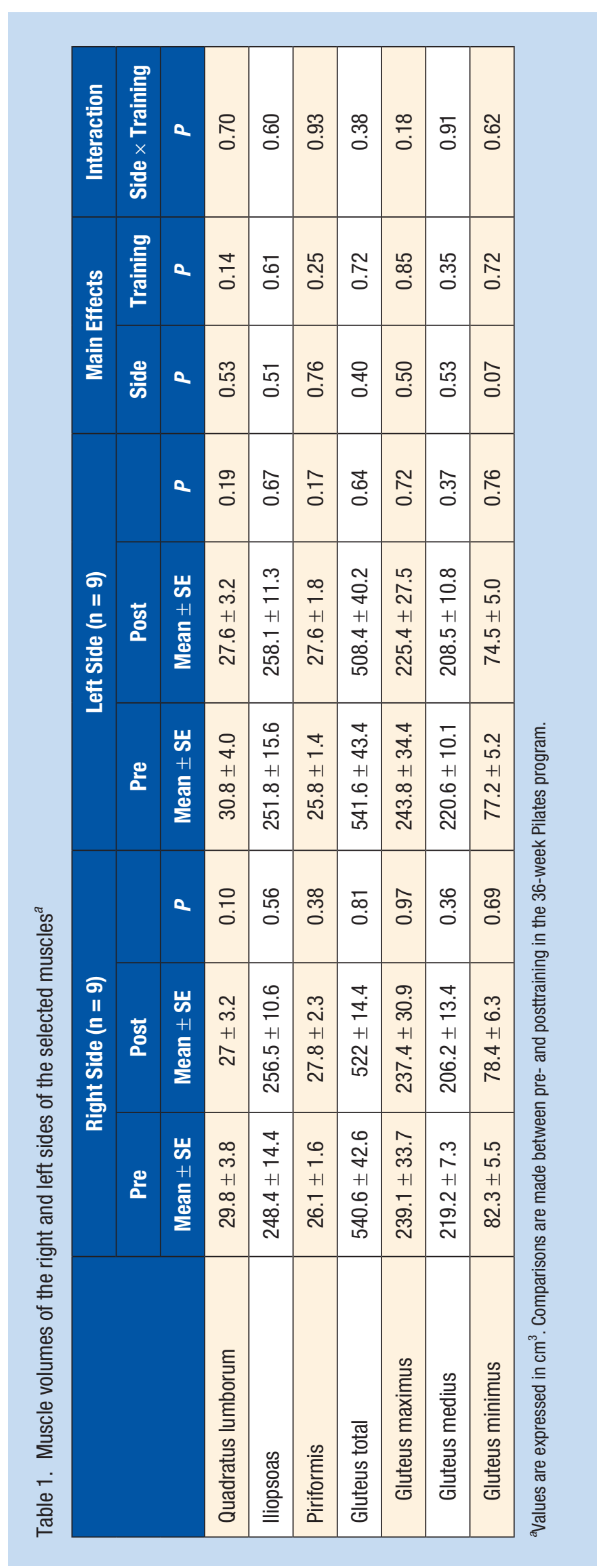




\section{REFERENCES}

1. Akagi R, Takai Y, Ohta M, Kanehisa H, Kawakami Y, Fukunaga T. Muscle volume compared to cross-sectional area is more appropriate for evaluating muscle strength in young and elderly individuals. Age Ageing. 2009;38:564-569

2. Barnouin $Y$, Butler-Browne G, Voit T, et al. Manual segmentation of individual muscles of the quadriceps femoris using MRI: a reappraisal. J Magn Reson Imaging. 2014;40:239-247.

3. Cruz-Ferreira A, Fernandes J, Gomes D, et al. Effects of pilates-based exercise on life satisfaction, physical self-concept and health status in adult women. Women Health. 2011;51:240-255.

4. Di Lorenzo CE. Pilates: what is it? Should it be used in rehabilitation? Sports Health. 2011;3:352-361.

5. Dorado C, Calbet JA, Lopez-Gordillo A, Alayon S, Sanchis-Moysi J. Marked effects of Pilates on the abdominal muscles: a longitudinal magnetic resonance imaging study. Med Sci Sports Exerc. 2012;44:1589-1594.

6. Elosua R, Garcia M, Aguilar A, Molina L, Covas MI, Marrugat J. Validation of the Minnesota Leisure Time Physical Activity Questionnaire in Spanish women. Investigators of the MARATDON Group. Med Sci Sports Exerc. 2000;32:1431-1437.

7. Engstrom CM, Walker DG, Kippers V, Mehnert AJ. Quadratus lumborum asymmetry and L4 pars injury in fast bowlers: a prospective MR study. Med Sci Sports Exerc. 2007;39:910-917.

8. Folland JP, Williams AG. The adaptations to strength training: morphological and neurological contributions to increased strength. Sports Med. 2007;37:145-168.

9. Fukunaga T, Miyatani M, Tachi M, Kouzaki M, Kawakami Y, Kanehisa H. Muscle volume is a major determinant of joint torque in humans. Acta Physiol Scand. 2001;172:249-255.

10. Ganderton C, Pizzari T, Harle T, Cook J, Semciw A. A comparison of gluteus medius, gluteus minimus and tensor facia latae muscle activation during gait in post-menopausal women with and without greater trochanteric pain syndrome. J Electromyogr Kinesiol. 2017;33:39-47.

11. Grimaldi A, Richardson C, Durbridge G, Donnelly W, Darnell R, Hides J. The association between degenerative hip joint pathology and size of the gluteus maximus and tensor fascia lata muscles. Man Ther. 2009;14:611-617.

12. Grimaldi A, Richardson C, Stanton W, Durbridge G, Donnelly W, Hides J. The association between degenerative hip joint pathology and size of the gluteus medius, gluteus minimus and piriformis muscles. Man Ther. 2009;14:605-610.

13. Hides J, Stanton W, Freke M, Wilson S, McMahon S, Richardson C. MRI study of the size, symmetry and function of the trunk muscles among elite cricketers with and without low back pain. Br J Sports Med. 2008;42:809-813.

14. Izumoto Y, Kurihara T, Suga T, Isaka T. Bilateral differences in the trunk muscle volume of skilled golfers. PLoS One. 2019;14:e0214752.

15. Jemmett RS, Macdonald DA, Agur AM. Anatomical relationships between selected segmental muscles of the lumbar spine in the context of multi-planar segmental motion: a preliminary investigation. Man Ther. 2004;9:203-210.

16. Kloubec JA. Pilates for improvement of muscle endurance, flexibility, balance, and posture. J Strength Cond Res. 2010;24:661-667.

17. Kwak L, Berrigan D, Van Domelen D, Sjostrom M, Hagstromer M. Examining differences in physical activity levels by employment status and/or job activity level: gender-specific comparisons between the United States and Sweden. JSci Med Sport. 2016;19:482-487.

18. Lim EC, Poh RL, Low AY, Wong WP. Effects of Pilates-based exercises on pain and disability in individuals with persistent nonspecific low back pain: a systematic review with meta-analysis. J Orthop Sports Phys Ther. 2011;41:70-80.

19. Mazloum V, Sahebozamani M, Barati A, Nakhaee N, Rabiei P. The effects of selective Pilates versus extension-based exercises on rehabilitation of low back pain. J Bodyw Mov Ther. 2018;22:999-1003.

20. McGill SM, Karpowicz A. Exercises for spine stabilization: motion/motor patterns, stability progressions, and clinical technique. Arch Phys Med Rebabil. 2009;90:118-126.

21. Nordez A, Jolivet E, Sudhoff I, Bonneau D, de Guise JA, Skalli W. Comparison of methods to assess quadriceps muscle volume using magnetic resonance imaging. J Magn Reson Imaging. 2009;30:1116-1123.

22. O'Brien TD, Reeves ND, Baltzopoulos V, Jones DA, Maganaris CN. Strong relationships exist between muscle volume, joint power and whole-body external mechanical power in adults and children. Exp Physiol. 2009;94:731-738.

23. Pata RW, Lord K, Lamb J. The effect of Pilates based exercise on mobility, postural stability, and balance in order to decrease fall risk in older adults. J Bodyw Mov Ther. 2014;18:361-367.

24. Pourahmadi M, Asadi M, Dommerholt J, Yeganeh A. Changes in the macroscopic morphology of hip muscles in low back pain. J Anat. 2019;236:3-20.

25. Ross R, Rissanen J, Pedwell H, Clifford J, Shragge P. Influence of diet and exercise on skeletal muscle and visceral adipose tissue in men. J Appl Physiol (1985). 1996;81:2445-2455.

26. Sanchis-Moysi J, Idoate F, Dorado C, Alayon S, Calbet JAL. Large asymmetric hypertrophy of rectus abdominis muscle in professional tennis players. PLOS One. 2010;5:e15858.

27. Sanchis-Moysi J, Idoate F, Izquierdo M, Calbet J, Dorado C. The hypertrophy of the lateral abdominal wall and quadratus lumborum is sport-specific: an MRI segmental study in professional tennis and soccer players. Sports Biomech. 2013;12:54-67.

28. Sanchis-Moysi J, Idoate F, Izquierdo M, Calbet JA, Dorado C. Iliopsoas and gluteal muscles are asymmetric in tennis players but not in soccer players. PLOS One. 2011;6:e22858.

29. Skorupska E, Keczmer P, Lochowski RM, Tomal P, Rychlik M, Samborski W. Reliability of MR-based volumetric 3-D analysis of pelvic muscles among subjects with low back with leg pain and healthy volunteers. PLoS One. 2016;11:e0159587.

30. Snijders CJ, Hermans PF, Kleinrensink GJ. Functional aspects of cross-legged sitting with special attention to piriformis muscles and sacroiliac joints. Clin Biomech (Bristol, Avon). 2006;21:116-121.

31. Stewart S, Stanton W, Wilson S, Hides J. Consistency in size and asymmetry of the psoas major muscle among elite footballers. BrJ Sports Med. 2010;44:1173-1177.

32. Wells C, Kolt GS, Bialocerkowski A. Defining Pilates exercise: a systematic review. Complement Ther Med. 2012;20:253-262.

33. Wells C, Kolt GS, Marshall P, Hill B, Bialocerkowski A. Effectiveness of Pilates exercise in treating people with chronic low back pain: a systematic review of systematic reviews. BMC Med Res Methodol. 2014;13:7.

For article reuse guidelines, please visit SAGE's website at http://www.sagepub.com/journals-permissions. 